\title{
Metastasis and Aggressiveness Marker
}

National Cancer Institute

\section{Source}

National Cancer Institute. Metastasis and Aggressiveness Marker. NCI Thesaurus. Code C18396.

A substance present in or produced by a tumor or by the host, that can be used for differentiating neoplasms that are likely to metastasize from those that are unlikely to metastasize. 